\title{
The Behavioral Effects of Combination Therapy of Memantine and Acetylcholinesterase Inhibitors Compared with Acetylcholinesterase Inhibitors Alone in Patients with Moderate Alzheimer's Dementia: A Double-Blind Randomized Placebo-Controlled Trial
}

\author{
HyunChul Youn ${ }^{1 *}$, Kang Joon Lee ${ }^{2 *}$, Shin-Gyeom Kim¹, Seong-Jin Cho ${ }^{3}$, Woo Jung Kim${ }^{4}$, \\ Won Joon Lee ${ }^{5}$, Jae Yeon Hwang ${ }^{5}$, Changsu Han ${ }^{6}$, Cheolmin Shin ${ }^{6}$, and Han-yong Jung ${ }^{1 \times}$ \\ ${ }^{1}$ Department of Psychiatry, Soonchunhyang University Bucheon Hospital, Bucheon, Republic of Korea \\ ${ }^{2}$ Department of Psychiatry, Ilsanpaik Hospital, Inje University College of Medicine, Goyang, Republic of Korea \\ ${ }^{3}$ Department of Psychiatry, Gil Medical Center, Gachon University College of Medicine, Incheon, Republic of Korea \\ ${ }^{4}$ Department of Psychiatry, Yongin Severance Hospital, Yonsei University College of Medicine, Yongin, Republic of Korea \\ ${ }^{5}$ Department of Psychiatry, Kangdong Sacred Heart Hospital, Hallym University College of Medicine, Seoul, Republic of Korea \\ ${ }^{6}$ Department of Psychiatry, Korea University College of Medicine, Seoul, Republic of Korea
}

Objective This study aimed to investigate treatment effects of combination therapy of memantine and acetylcholinesterase inhibitors (AchEIs) compared with AchEIs alone on behavioral and psychological symptoms of dementia (BPSD) in patients with moderate Alzheimer's dementia (AD).

Methods This was a 12-week, double-blind, randomized, placebo-controlled trial. A total of 148 patients with moderate AD participated in this study. Mini-Mental State Examination, Neuropsychiatric Inventory (NPI), Clinician's Interview-Based Impression of Change plus caregiver input, Gottfries-Bråne-Steen Scale, and Zarit Burden Interview were used as assessment scales.

Results There were no significant differences in age, sex, or education between AChEIs alone and combination groups. The combination group showed significantly more improvement of NPI-disinhibition score $(0.76 \pm 2.15)$ than the AChEIs alone group $(-0.14 \pm 1.71)$ after 12 weeks.

Conclusion Our findings suggest that the combination therapy of memantine and AchEIs might be a beneficial option for reducing disinhibition symptoms of patients with moderate $\mathrm{AD}$ compared with AchEIs alone. We believe that clinicians need to consider additional memantine treatment when patients with moderate $\mathrm{AD}$ complain disinhibition symptom. A larger clinical trial is needed to further determine the efficacy and advantages of such combination therapy of memantine and AchEIs for treating BPSD of patients with moderate AD.

Psychiatry Investig 2021;18(3):233-240

Key Words Alzheimer's dementia, Memantine, Acetylcholinesterase inhibitors, Behavioral and psychological symptoms of dementia, Disinhibition, Neuropsychiatric inventory.

\section{INTRODUCTION}

Dementia has been an important issue in many countries due to worldwide trend of population aging. ${ }^{1}$ In South Korea, Received: August 28, 2020 Revised: December 18, 2020 Accepted: January 13, 2021

\footnotetext{
$\triangle$ Correspondence: Han-yong Jung, MD, PhD
}

Department of Psychiatry, Soonchunhyang University Bucheon Hospital, 170 Jomaru-ro, Bucheon 14584, Republic of Korea

Tel: +82-32-621-5063, Fax: +82-32-621-6950, E-mail: hanyjung@schmc.ac.kr

*These authors contributed equally to this work.

(c) This is an Open Access article distributed under the terms of the Creative Commons Attribution Non-Commercial License (https://creativecommons.org/licenses/bync/4.0) which permits unrestricted non-commercial use, distribution, and reproduction in any medium, provided the original work is properly cited. the number of patients with dementia has continuously increased due to a very rapid rate of population aging. ${ }^{2}$ According to the National Institute of Dementia, 750,488 persons were estimated to have dementia (about $10.16 \%$ of people aged 65 and over) in South Korea in 2019. ${ }^{3}$ Social cost per year per patient with dementia was estimated at 20,420,000 Korean Won (KW; 1 USD $=1,206 \mathrm{KW}$ as of 2020). ${ }^{3}$ Total public management cost for patients with dementia was estimated at 15,300 billion KW (i.e., 12,700 million USD). ${ }^{3}$ It has been predicted that cost for patients with dementia would increase to 3 million by 2050 in South Korea. ${ }^{3}$ Accordingly, social cost will increase rapidly. 
Social cost of dementia is closely associated with behavioral and psychological symptoms of dementia (BPSD) $)^{4-6}$ because BPSD can increase caregiver distress and nursing home placement. ${ }^{4,7}$ Many clinicians and researchers have focused on alleviating BPSD such as insomnia, anxiety, aggression, agitation, delusion, hallucination, disinhibition, and wandering. ${ }^{8}$ Trinh et al. ${ }^{9}$ have shown that the efficacy of acetylcholinesterase inhibitors (AchEIs) commonly used for cognitive symptom of Alzheimer's dementia (AD) is insufficient for treating BPSD. Some studies have recommended low-dose antipsychotics (aripiprazole, olanzapine, risperidone, quetiapine, and haloperidol) for treating agitation and aggression in patients with dementia. ${ }^{10,11}$ Selective serotonin reuptake inhibitors have also been used for reducing depression and agitation. ${ }^{11,12}$ In addition, benzodiazepine and carbamazepine have been studied for treating BPSD, although common use of these medications is not recommended due to side effects and drug interactions. ${ }^{13,14} \mathrm{Up}$ to date, consensus and guideline regarding medications for treating BPSD in patients with dementia have not been established yet.

Memantine is an uncompetitive (channel blocking) Nmethyl-D-aspartate receptor antagonist. It was approved for treating moderate-to-severe AD by Food and Drug Administration in 2003. ${ }^{8,15}$ Many researchers have studied the effect of memantine in patients with $\mathrm{AD} .{ }^{16-18}$ Parsons et al. ${ }^{19}$ have shown that a combination therapy of memantine and AchEIs has complementary and synergistic effects. However, there is still not enough evidence to verify the effect of memantine for treating BPSD, though memantine has been one candidate medication for treating BPSD in patients with $\mathrm{AD}$.

In this study, we conducted a double-blind, randomized, placebo-controlled trial to investigate the effect of combination therapy of memantine and AchEIs compared with AchEIs alone for treating BPSD in patients with moderate AD.

\section{METHODS}

\section{Study design}

This was a 12-week, multi-center (six), prospective, doubleblind, randomized, placebo-controlled, parallel group trial. The trial was registered (registration number: IIT 16395T). The trial was initiated on Apr. 26, 2016. All visits were completed by Oct. 23, 2019. This study was approved by the Institutional Review Board of Inje University Ilsan Paik Hospital (2015-06-008), Soonchunhyang University Bucheon Hospital (2015-07-018), Gachon University Gil Medical Center, Myongji Hospital (MJH 2017-09-034), Gangdong Sacred Heart Hospital (2018-08-006), and Korea University Ansan Hospital (2015AS0096). All subjects and their legal guardians (family members or caregivers) were informed of the study protocol.
They provided written informed consent.

\section{Subjects}

A total of 148 older adults from Inje University Ilsan Paik Hospital ( $\mathrm{n}=48 ; 32.4 \%)$, Soonchunhyang University Bucheon Hospital ( $\mathrm{n}=34 ; 23.0 \%)$, Gachon University Gil Medical Center ( $\mathrm{n}=30 ; 20.3 \%)$, Myongii Hospital ( $\mathrm{n}=27$; 18.2\%), Gangdong Sacred Heart Hospital ( $n=5 ; 3.4 \%)$, and Korea University Ansan Hospital ( $\mathrm{n}=4 ; 2.7 \%)$ participated in this study. This study enrolled patients with $\mathrm{AD}$ who met the criteria for "major neurocognitive disorder due to Alzheimer's disease" proposed by the fifth version of the Diagnostic and Statistical Manual for Mental Disorders (DSM-5) ${ }^{20}$ We enrolled patients with moderate $\mathrm{AD}$ considering the indication of memantine and the onset timing of BPSD. ${ }^{8}$

Subjects enrolled for this study met the following inclusion criteria: 1) aged over 60 years old, 2) scored 10-20 in MiniMental State Examination (MMSE), 3) scored $\geq 11$ in Neuropsychiatric Inventory (NPI), 4) took AchEIs for over six months, including donepezil, rivastigmine, and galantamine, 5) had unchanged AchEIs dosages for at least three months, 6) had caregiver who could provide reliable information and accompany participants whenever visiting the hospital during the study period. During screening and diagnostic procedures, we applied the following patient exclusion criteria: 1) those who had experienced cerebrovascular diseases or traumatic brain diseases, 2) those who had alcohol or other substance use disorders, 3) those who had fatal or serious medical diseases, and 4) those who had visual or hearing impairment at a level where assessments for studies including neuropsychological tests and clinical scales were impossible. Geriatric psychiatrists certified by Korean Association for Geriatric Psychiatry were responsible for all screening and diagnostic procedures.

\section{Assessment}

At baseline assessment, demographic data such as age, sex, and years of education were obtained. In addition, all participants and their caregivers used the following scales during the study period.

MMSE is a simple measure of cognitive function that has been used in clinical evaluation of patients with dementia. ${ }^{21}$ Among various Korean versions of MMSE, we adopted the MMSE-KC version: MMSE in the Korean version of Consortium to Establish a Registry for Alzheimer's disease (CERAD) assessment packet. ${ }^{22}$ NPI was conducted to assess behavioral and psychiatric symptoms of dementia. ${ }^{23}$ NPI consisted of 12 symptoms. Each symptom was scored according to its frequency and severity. ${ }^{23}$ We used Korean version of NPI and adopted the sum of composite scores (frequency x severity). ${ }^{24}$ 
This study also used Clinician's Interview-Based Impression of Change plus caregiver input (CIBIC-Plus). ${ }^{25}$ CIBIC-Plus is a clinician rating scale that evaluates change in patients' overall condition. Gottfries-Bråne-Steen Scale (GBS) focuses on the overall assessment of patients with dementia. ${ }^{26} \mathrm{GBS}$ consists of subscales regarding cognition, emotion, activities of daily living, and behavioral and psychological symptoms. We adopted GBS for caregiver interview. In addition, we adopted Zarit Burden Interview (ZBI) for interviewing caregivers of patients with dementia. ${ }^{27,28} \mathrm{ZBI}$ has been widely used to assess caregiver burden related to dementia.

\section{Procedure}

Subjects were randomized using a stratified block randomization method. Statisticians who were blinded to clinical information conducted a 1:1 ratio randomization using Statistical Analysis System (SAS Institute Inc. Cary, NC, USA). All participants took memantine or placebo two times a day dur-

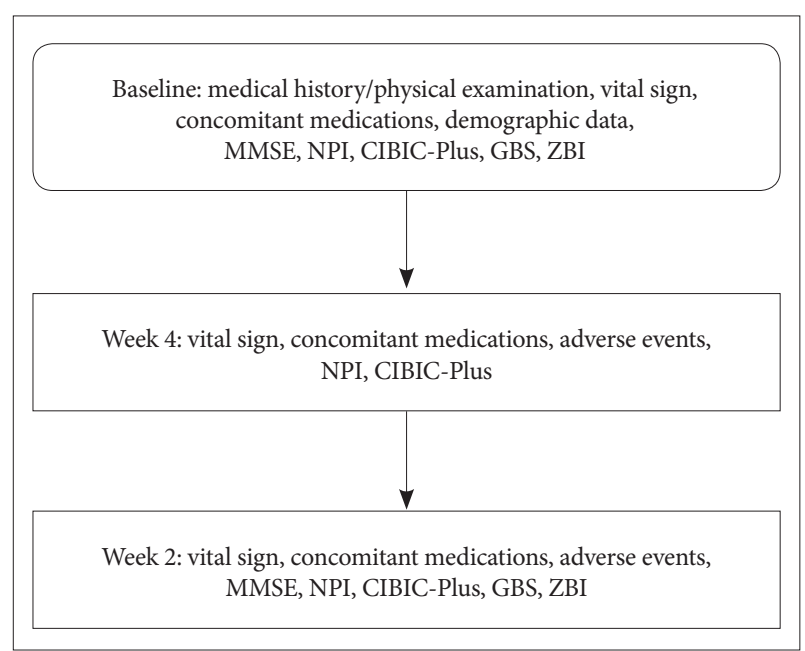

Figure 1. The schedule for assessments. MMSE: Mini-Mental State Examination, NPI: Neuropsychiatric Inventory, CIBIC-Plus: Clinician's Interview-Based Impression of Change plus caregiver input, GBS: Gottfries- Bråne-Steen Scale, ZBI: Zarit Burden Interview. ing 12 weeks according to their randomized group allocation. Memantine and placebo had the same appearance. They were provided using blister packs. Participants in the combination group initially received $5 \mathrm{mg}$ memantine per day. The dosage of memantine was then increased to $20 \mathrm{mg}$ /day between 3 and 8 weeks considering side effects. Medication adherence was monitored using pill count method referring to remaining empty blister packs. Antidepressants/benzodiazepines/cognitive enhancers-unchanged medication dosages for at least three months-and medications for physical illness were permitted during the study period. However, the following medications were not allowed to be co-administered until the end of this study: amantadine, ketamine, detromethorphan, phenytoin, cimetidine, ranitidine, procainamide, quinidine, quinine, and nicotine. Figure 1 shows the schedule for assessments including effectiveness and safety.

\section{Statistical analysis}

Descriptive statistics were calculated for all variables. Percentages were calculated for categorical variables while means and standard deviations were calculated for continuous variables. Independent $t$-test was used for analyzing differences in baseline characteristics and changes of scale scores between AChEIs alone and combination groups. The last observation carried forward (LOCF) approach was adopted to handle missing data.

A p-value of $<0.05$ was considered statistically significant. All statistical analyses were performed using $\mathrm{R}$ version 3.6.2 (The R Foundation for Statistical Computing Platform, Vienna, Austria).

\section{RESULTS}

Table 1 shows basic characteristics of the AChEIs alone and combination groups. The mean age of subjects was $78.18 \pm$ 6.85 years in the AChEIs alone group and $78.23 \pm 6.59$ years in

Table 1. Baseline characteristics of participants in AchEls alone and combination groups

\begin{tabular}{|c|c|c|c|c|c|}
\hline & Total $(\mathrm{N}=148)$ & AchEIs alone $(\mathrm{N}=74)$ & Combination $(\mathrm{N}=74)$ & t-value & p-value* \\
\hline Age (years) & $78.20 \pm 6.69$ & $78.18 \pm 6.85$ & $78.23 \pm 6.59$ & -0.05 & 0.963 \\
\hline Sex (male/female) & $39 / 109$ & $18 / 56$ & $21 / 53$ & 0.56 & 0.579 \\
\hline Education (years) & $6.95 \pm 5.07$ & $6.69 \pm 5.11$ & $7.22 \pm 5.05$ & -0.63 & 0.527 \\
\hline MMSE & $15.61 \pm 3.41$ & $15.71 \pm 3.35$ & $15.51 \pm 3.50$ & 0.36 & 0.717 \\
\hline NPI & $24.59 \pm 16.43$ & $24.73 \pm 15.31$ & $24.45 \pm 17.60$ & 0.10 & 0.920 \\
\hline CIBIC-Plus & $4.13 \pm 0.69$ & $4.10 \pm 0.68$ & $4.15 \pm 0.71$ & -0.47 & 0.641 \\
\hline GBS & $43.12 \pm 24.04$ & $43.44 \pm 24.30$ & $42.79 \pm 23.94$ & 0.16 & 0.872 \\
\hline $\mathrm{ZBI}$ & $34.59 \pm 17.59$ & $36.74 \pm 17.15$ & $32.40 \pm 17.88$ & 1.49 & 0.138 \\
\hline
\end{tabular}

${ }^{*}$ p values were calculated using chi-square test and independent t-test. MMSE: Mini-Mental State Examination, NPI: Neuropsychiatric Inventory, CIBIC-Plus: Clinician's Interview-Based Impression of Change plus caregiver input, GBS: Gottfries- Bråne-Steen Scale, ZBI: Zarit Burden Interview 
the combination group. More females than males participated in both groups. There were no significant differences in age, sex, or education between AChEIs alone and combination groups. No one specifically complained about the symptoms of side effects, and no one stopped taking drugs because of drug adverse events.

Changes of scale scores in AChEIs alone and combination groups during the follow-up period are shown in Tables 2 and 3 . The combination group showed significantly more improvement of NPI-disinhibition score $(0.76 \pm 2.15)$ than the AChEIs alone group $(-0.14 \pm 1.71)$ after 12 weeks, although there was no significant difference in this score between the two groups at week 4. CIBIC-Plus change scores did not differ significantly between the two groups at week 4 or week 12 (Table 4).

\section{DISCUSSION}

South Korea has national health insurance system which covers all health services of approximately 50 million Koreans. ${ }^{29}$ Accordingly, almost all medications are controlled by criteria for National Health Insurance coverage. Recommended National Health Insurance criterion for memantine prescription is MMSE $\leq 20$ (and Clinical Dementia Rating 2-3 or Global Deterioration Scale 4-7). According to 2019 statistics of National Institute of Dementia, the target population of memantine use in South Korea was estimated to be approximately $350,000 .{ }^{3}$ There were about 220,000 patients with moderate degree of $\mathrm{AD}$ in that report, consistent with the inclusion criteria of our study. ${ }^{3}$ Although statistics data are limited, the prevalence of BPSD is relatively high (50-80\%) in patients with dementia. ${ }^{30-32}$ Therefore, many older adults can get help if the effect of memantine for treating BPSD is confirmed.

Previous double-blind, randomized, placebo-controlled studies have reported the effect of combination therapy of memantine and AchEIs. Tariot et al..$^{33}$ have enrolled 404 patients with AD (MMSE of 5 to 14) and found that patients in the memantine group have significantly better outcomes than those in placebo group based on measures of cognition, activities of daily living, global outcome, and behavior. Grossberg et al. ${ }^{34}$ have also reported that patients with AD (MMSE of 3 to 14) in the memantine group have cognitive, global, and behavioral benefits. However, some studies on $\mathrm{AD}$ patients with relatively less severe stages have shown different results. Porsteinsson et al. ${ }^{35}$ have included $433 \mathrm{AD}$ patients with MMSE of 10 to 22 and found that those in the memantine group do not show an advantage over those in the placebo group regarding cognition, activities of daily living, global outcome, or behavior. Similarly, Choi et al. ${ }^{36}$ have reported that the combination therapy of memantine plus rivastigmine patch does not show an advantage over rivastigmine patch monotherapy in patients with $\mathrm{AD}$ (50 to 90 years old with MMSE of 10 to 20). Our study found that patients with moderate $\mathrm{AD}$ treated with the combination therapy of memantine and AchEIs had significant improvement in disinhibition symptoms of BPSD compared with those who treated with AchEIs alone. Considering that previous studies did not validate an advantage of combination therapy of memantine plus AchEIs in patients with moderate $\mathrm{AD}$, the result of our study might be used as a reference when treating patients with moderate $\mathrm{AD}$.

Causes and pathophysiology of BPSD are incompletely understood. ${ }^{37}$ Likewise, pathophysiology, phenomenology, main clinical correlates, and long-term evolution of disinhibition symptom in dementia remain unclear. ${ }^{38}$ Accordingly, it might be difficult to elucidate the association between memantine and improvement of disinhibition symptoms. Povysheva and Johnson have suggested that memantine can affect excitationinhibition balance in the prefrontal cortex. ${ }^{39}$ Araki et al. ${ }^{40}$ have reported that combination treatment of memantine and donepezil can inhibit the reduction of cerebral blood flow in the prefrontal area of a patient with $\mathrm{AD}$. Considering that prefrontal cortex is one of the regions associated with disinhibition symptom, these previous studies might help explain results of our analysis. ${ }^{41}$

The question of NPI-disinhibition item is "Does the patient seem to act impulsively, for example, talking to strangers as if he/she knows them, or saying things that may hurt people's feelings?"23 Lyketsos et al. ${ }^{42}$ have shown that the prevalence of NPI-disinhibition item is $12.7 \%$ in patients with dementia. Kaufer et al. ${ }^{43}$ have also reported a prevalence of $10-13 \%$ of NPI-disinhibition item in patients with moderate to severe dementia. In addition, Starkstein et al. ${ }^{38}$ have investigated the prevalence of abnormal behaviors in patients with dementia and reported that inappropriate social behavior is one of the most frequent symptoms. Therefore, clinicians may often encounter $\mathrm{AD}$ patients with disinhibition symptoms. The use of additional memantine might be considered each time.

Our findings suggest that the combination therapy of memantine and AchEIs might be a beneficial option for reducing disinhibition symptoms of patients with moderate $\mathrm{AD}$ compared with AchEIs alone. That is, combination therapy of memantine and AchEIs may be considered when disinhibition symptoms of patients with moderate $\mathrm{AD}$ are encountered or when disinhibition symptoms are unresponsive to AchEIs only. An additional implication of this study is that it suggests the possibility of using memantine combination therapy for patients with moderate AD for treating BPSD. A larger clinical trial is needed to further determine the efficacy and advantages of such combination therapy of memantine and AchEIs for treating BPSD of patients with moderate AD. 


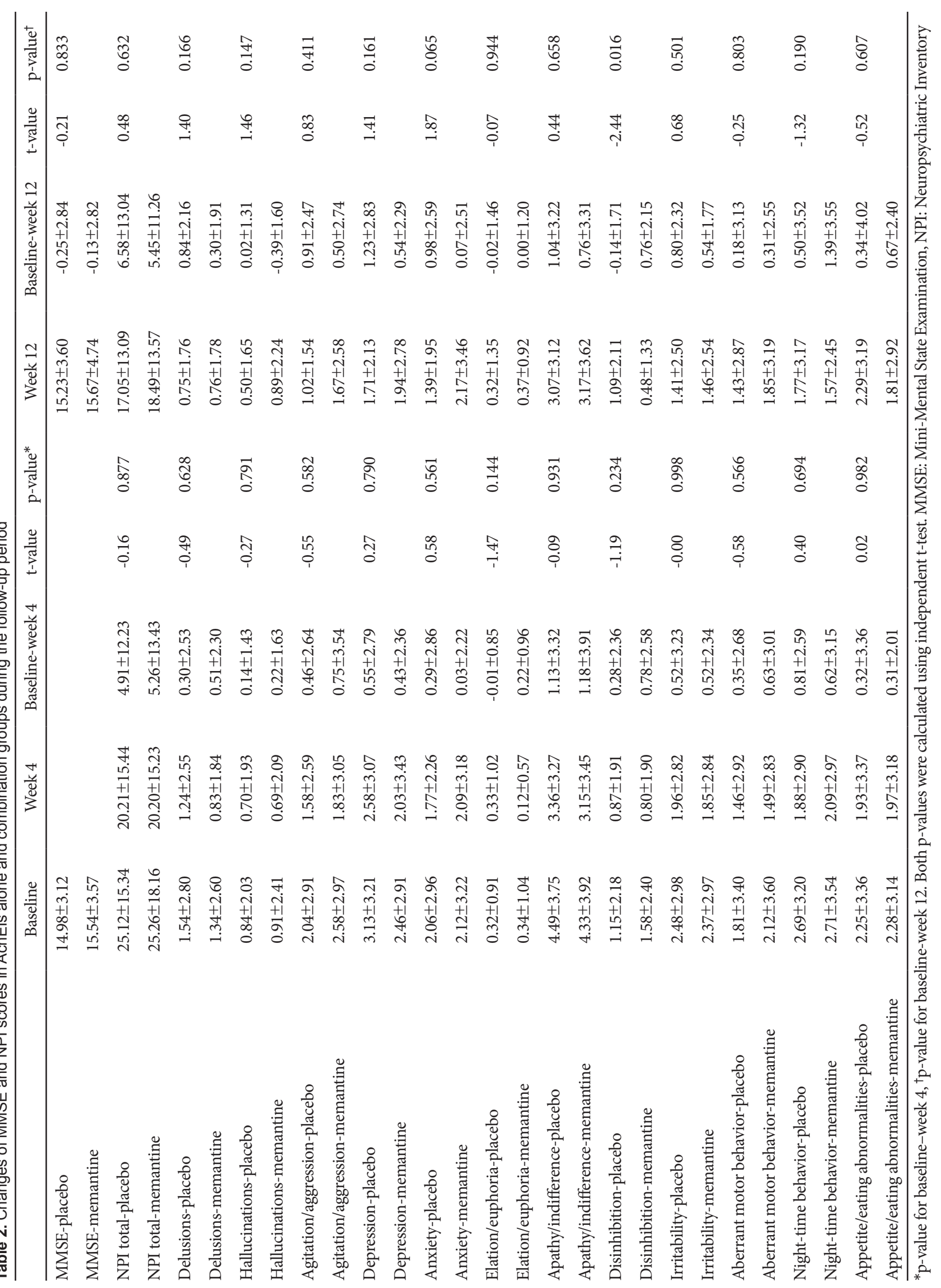




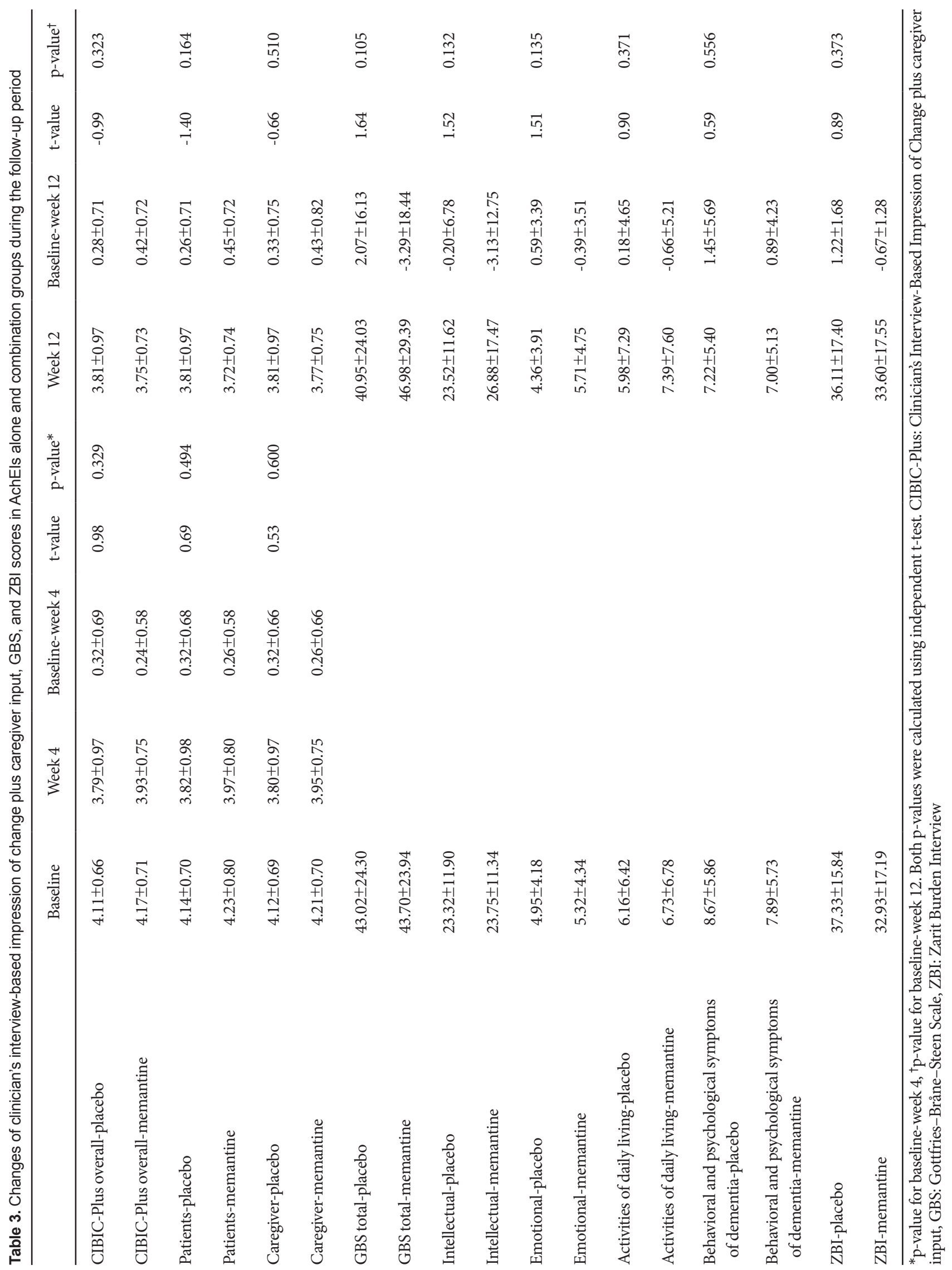


$\mathrm{HC}$ Youn et al.

Table 4. Clinician's interview-based impression of change plus caregiver input change scores of participants in AchEls alone and combination groups

\begin{tabular}{|c|c|c|c|c|c|c|}
\hline & Week 4 & $\mathrm{t}$-value & p-value* & Week 12 & t-value & p-value ${ }^{\dagger}$ \\
\hline CIBIC-Plus overall-placebo (change) & $3.65 \pm 0.95$ & 0.14 & 0.890 & $3.49 \pm 0.87$ & -0.62 & 0.538 \\
\hline CIBIC-Plus overall-memantine (change) & $3.63 \pm 0.74$ & & & $3.58 \pm 0.69$ & & \\
\hline Patients-placebo (change) & $3.68 \pm 0.95$ & 0.03 & 0.974 & $3.49 \pm 0.87$ & -0.38 & 0.708 \\
\hline Patients-memantine (change) & $3.68 \pm 0.75$ & & & $3.55 \pm 0.67$ & & \\
\hline Caregiver-placebo (change) & $3.65 \pm 0.94$ & -0.17 & 0.867 & $3.51 \pm 0.91$ & -0.70 & 0.484 \\
\hline Caregiver-memantine (change) & $3.68 \pm 0.79$ & & & $3.62 \pm 0.74$ & & \\
\hline
\end{tabular}

${ }^{*} \mathrm{p}$-value for week $4,{ }^{\dagger} \mathrm{p}$-value for week 12 . Both p-values were calculated using independent t-test. CIBIC-Plus: Clinician's Interview-Based Impression of Change plus caregiver input

However, this study has some limitations. First, the sample size of this study was relatively small and most of our participants were females, thus limiting the generalizability of our results. Second, this study adopted only the MMSE score as an inclusion criterion for moderate $\mathrm{AD}$. We believe that a more complex neuropsychiatric battery such as CERAD is needed for more appropriate classification. Third, our study analyzed the effect of combination therapy of memantine and AchEIs in patients with moderate AD. Further studies including other $\mathrm{AD}$ groups with various severity stages are needed to provide more informative results. Fourth, the follow-up period of this study was 12 weeks. Considering that patients taking memantine and AchEIs tend to maintain their medications for a long time, a longer follow-up period may be necessary. Finally, this study did not match kinds or doses of AchEIs. In addition, we also did not control kinds or doses of other drugs such as antidepressants, antipsychotics, and medications for physical illness. More controlled studies that address this issue are needed to verify the effect of such memantine combination therapy more clearly.

This study conducted a double-blind, randomized, placebocontrolled trial to investigate the effect of combination therapy of memantine and AchEIs compared with AchEIs alone in patients with moderate $\mathrm{AD}$. After 12 weeks of follow-up period, patients in the combination group showed an advantage over those in the AChEIs alone group for NPI-disinhibition items. We believe that clinicians may consider additional memantine treatment when patients with moderate $\mathrm{AD}$ complain disinhibition symptoms. Further larger clinical trials are needed to verify and determine advantages of such combination therapy of memantine and AchEIs for treating BPSD of patients with moderate $\mathrm{AD}$.

\section{Acknowledgments}

This work was supported by a grant from Lundbeck Korea Co., Ltd. Overall data acquisition, statistical analyses, and interpretation of the study results were implemented with no input from the pharmaceutical company. This study was also supported by the Soonchunhyang Research Fund.

\section{Conflicts of Interest}

The authors have no potential conflicts of interest to disclose.

\section{Author Contributions}

Conceptualization: Kang Joon Lee, Seong-Jin Cho, Woo Jung Kim, Won Joon Lee, Changsu Han, Han-yong Jung. Data curation: Kang Joon Lee, Shin-Gyeom Kim, Seong-Jin Cho, Woo Jung Kim, Won Joon Lee, Jae Yeon Hwang, Changsu Han, Cheolmin Shin, Han-yong Jung. Formal analysis: Kang Joon Lee, Han-yong Jung. Funding acquisition: Han-yong Jung. Investigation: Kang Joon Lee, Shin-Gyeom Kim, Seong-Jin Cho, Woo Jung Kim, Won Joon Lee, Jae Yeon Hwang, Changsu Han, Cheolmin Shin, Hanyong Jung. Methodology: HyunChul Youn, Kang Joon Lee, Han-yong Jung. Project administration: Kang Joon Lee, Han-yong Jung. Resources: Kang Joon Lee, Han-yong Jung. Supervision: Kang Joon Lee, Han-yong Jung. Validation: Kang Joon Lee, Han-yong Jung. Writing_original draft: HyunChul Youn. Writing_-review \& editing: HyunChul Youn, Kang Joon Lee, Han-yong Jung.

\section{ORCID iDs}

$\begin{array}{ll}\text { HyunChul Youn } & \text { https://orcid.org/0000-0002-6557-5628 } \\ \text { Kang Joon Lee } & \text { https://orcid.org/0000-0001-8867-0276 } \\ \text { Shin-Gyeom Kim } & \text { https://orcid.org/0000-0001-8196-655X } \\ \text { Seong-Jin Cho } & \text { https://orcid.org/0000-0002-8814-5807 } \\ \text { Woo Jung Kim } & \text { https://orcid.org/0000-0002-4963-4819 } \\ \text { Won Joon Lee } & \text { https://orcid.org/0000-0002-6258-1790 } \\ \text { Jae Yeon Hwang } & \text { https://orcid.org/0000-0002-0616-9750 } \\ \text { Changsu Han } & \text { https://orcid.org/0000-0002-4021-8907 } \\ \text { Cheolmin Shin } & \text { https://orcid.org/0000-0002-8232-2921 } \\ \text { Han-yong Jung } & \text { https://orcid.org/0000-0003-0089-0368 }\end{array}$

\section{REFERENCES}

1. Xu J, Qiu C. Worldwide Economic Costs and Societal Burden of Dementia. In: Perneczky R, Editor. Biomarkers for Preclinical Alzheimer's Disease. New York: Springer, 2018, p.3-13.

2. Han JW, Kim TH, Kwak KP, Kim K, Kim BJ, Kim SG, et al. Overview of the Korean Longitudinal Study on Cognitive Aging and Dementia. Psychiatry Investig 2018;15:767-774.

3. National Institute of Dementia. Korean Dementia Observatory 2019. Seoul: Ministry of Health and Welfare, National Institute of Dementia; 2020.

4. Beeri MS, Werner P, Davidson M, Noy S. The cost of behavioral and psychological symptoms of dementia (BPSD) in community dwelling Alzheimer's disease patients. Int J Geriatr Psychiatry 2002;17:403-408.

5. Lowery D, Warner J. Behavioural and psychological symptoms of dementia (BPSD): the personal and practical costs of dementia. J Integr Care 2009;17:13-19.

6. Olazaran-Rodriguez J, Aguera-Ortiz LF, Muniz-Schwochert R. Psycho- 
logical and behavioural symptoms of dementia: prevention, diagnosis and treatment. Rev Neurol 2012;55:598-608.

7. Teri L. Behavior and caregiver burden: behavioral problems in patients with Alzheimer disease and its association with caregiver distress. Alzheimer Dis Assoc Disord 1997;11(Suppl 4):S35-S38.

8. Youn H, Jeong HG. Pharmacotherapy for dementia. J Korean Med Assoc 2018;61:758-764.

9. Trinh NH, Hoblyn J, Mohanty S, Yaffe K. Efficacy of cholinesterase inhibitors in the treatment of neuropsychiatric symptoms and functional impairment in Alzheimer disease: a meta-analysis. JAMA 2003;289:210216.

10. Azermai M. Dealing with behavioral and psychological symptoms of dementia: a general overview. Psychol Res Behav Manag 2015;8:181-185.

11. Wang F, Feng TY, Yang S, Preter M, Zhou JN, Wang XP. Drug Therapy for Behavioral and Psychological Symptoms of Dementia. Curr Neuropharmacol 2016;14:307-313.

12. Bains J, Birks J, Dening T. Antidepressants for treating depression in dementia. Cochrane Database Syst Rev 2002;4:CD003944.

13. Tampi RR, Tampi DJ. Efficacy and tolerability of benzodiazepines for the treatment of behavioral and psychological symptoms of dementia: a systematic review of randomized controlled trials. Am J Alzheimers Dis Other Demen 2014;29:565-574.

14. Pinheiro D. [Anticonvulsant mood stabilizers in the treatment of behavioral and psychological symptoms of dementia (BPSD)]. Encephale 2008;34:409-415.

15. Rogawski MA, Wenk GL. The neuropharmacological basis for the use of memantine in the treatment of Alzheimer's disease. CNS Drug Rev 2003;9:275-308.

16. McShane R, Areosa Sastre A, Minakaran N. Memantine for dementia. Cochrane Database Syst Rev 2006;2:CD003154.

17. Winblad B, Jones RW, Wirth Y, Stoffler A, Mobius HJ. Memantine in moderate to severe Alzheimer's disease: a meta-analysis of randomised clinical trials. Dement Geriatr Cogn Disord 2007;24:20-27.

18. Johnson JW, Kotermanski SE. Mechanism of action of memantine. Curr Opin Pharmacol 2006;6:61-67.

19. Parsons CG, Danysz W, Dekundy A, Pulte I. Memantine and cholinesterase inhibitors: complementary mechanisms in the treatment of Alzheimer's disease. Neurotox Res 2013;24:358-369.

20. American Psychiatric Association. Diagnostic and Statistical Manual of Mental Disorders: DSM- $5^{\mathrm{TM}}$. 5th Ed. Arlington, VA: American Psychiatric Publishing, Inc; 2013.

21. Folstein MF, Folstein SE, McHugh PR. "Mini-mental state". A practical method for grading the cognitive state of patients for the clinician. J Psychiatr Res 1975;12:189-198.

22. Lee DY, Lee KU, Lee JH, Kim KW, Jhoo JH, Youn JC, et al. A normative study of the mini-mental state examination in the Korean elderly. J Korean Neuropsychiatr Assoc 2002;41:508-525.

23. Cummings JL, Mega M, Gray K, Rosenberg-Thompson S, Carusi DA, Gornbein J. The Neuropsychiatric Inventory: comprehensive assessment of psychopathology in dementia. Neurology 1994;44:2308-2314.

24. Choi SH, Na DL, Kwon HM, Yoon SJ, Jeong JH, Ha CK. The Korean version of the neuropsychiatric inventory: a scoring tool for neuropsychiatric disturbance in dementia patients. J Korean Med Sci 2000;15: 609-615.

25. Reisberg B, Schneider L, Doody R, Anand R, Feldman H, Haraguchi $\mathrm{H}$, et al. Clinical global measures of dementia. Position paper from the International Working Group on Harmonization of Dementia Drug Guidelines. Alzheimer Dis Assoc Disord 1997;11 (Suppl 3):8-18.

26. Gottfries CG, Brane G, Gullberg B, Steen G. A new rating scale for dementia syndromes. Arch Gerontol Geriatr 1982;1:311-330.
27. Zarit SH, Todd PA, Zarit JM. Subjective burden of husbands and wives as caregivers: a longitudinal study. Gerontologist 1986;26:260-266.

28. Bae KY, Shin IS, Kim SW, Kim JM, Yang SJ, Mun JU, et al. Care burden of caregivers according to cognitive function of elderly persons. J Korean Soc Biol Ther Psychiatry 2006;12:66-75.

29. Youn H, Lee S, Han SW, Kim LY, Lee TS, Oh MJ, et al. Obstetric risk factors for depression during the postpartum period in South Korea: a nationwide study. J Psychosom Res 2017;102:15-20.

30. Margallo-Lana M, Swann A, O’Brien J, Fairbairn A, Reichelt K, Potkins $\mathrm{D}$, et al. Prevalence and pharmacological management of behavioural and psychological symptoms amongst dementia sufferers living in care environments. Int J Geriatr Psychiatry 2001;16:39-44.

31. Haibo X, Shifu X, Pin NT, Chao C, Guorong M, Xuejue L, et al. Prevalence and severity of behavioral and psychological symptoms of dementia (BPSD) in community dwelling Chinese: findings from the Shanghai three districts study. Aging Ment Health 2013;17:748-752.

32. van der Linde RM, Dening T, Stephan BC, Prina AM, Evans E, Brayne C. Longitudinal course of behavioural and psychological symptoms of dementia: systematic review. Br J Psychiatry 2016;209:366-377.

33. Tariot PN, Farlow MR, Grossberg GT, Graham SM, McDonald S, Gergel I, et al. Memantine treatment in patients with moderate to severe Alzheimer disease already receiving donepezil: a randomized controlled trial. JAMA 2004;291:317-324.

34. Grossberg GT, Manes F, Allegri RF, Gutiérrez-Robledo LM, Gloger S, Xie L, et al. The safety, tolerability, and efficacy of once-daily memantine (28 mg): a multinational, randomized, double-blind, placebo-controlled trial in patients with moderate-to-severe Alzheimer's disease taking cholinesterase inhibitors. CNS Drugs 2013;27:469-478.

35. Porsteinsson AP, Grossberg GT, Mintzer J, Olin JT, Memantine MEMMDSG. Memantine treatment in patients with mild to moderate Alzheimer's disease already receiving a cholinesterase inhibitor: a randomized, double-blind, placebo-controlled trial. Curr Alzheimer Res 2008;5:83-89.

36. Choi SH, Park KW, Na DL, Han HJ, Kim EJ, Shim YS, et al. Tolerability and efficacy of memantine add-on therapy to rivastigmine transdermal patches in mild to moderate Alzheimer's disease: a multicenter, randomized, open-label, parallel-group study. Curr Med Res Opin 2011;27: 1375-1383.

37. Carotenuto A, Rea R, Traini E, Fasanaro AM, Ricci G, Manzo V, et al. The Effect of the Association between Donepezil and Choline Alphoscerate on Behavioral Disturbances in Alzheimer's Disease: Interim Results of the ASCOMALVA Trial. J Alzheimers Dis 2017;56:805-815.

38. Starkstein SE, Garau ML, Cao A. Prevalence and clinical correlates of disinhibition in dementia. Cogn Behav Neurol 2004;17:139-147.

39. Povysheva NV, Johnson JW. Effects of memantine on the excitation-inhibition balance in prefrontal cortex. Neurobiol Dis 2016;96:75-83.

40. Araki T, Wake R, Miyaoka T, Kawakami K, Nagahama M, Furuya M, et al. The effects of combine treatment of memantine and donepezil on Alzheimer's disease patients and its relationship with cerebral blood flow in the prefrontal area. Int J Geriatr Psychiatry 2014;29:881-889.

41. Zamboni G, Huey ED, Krueger F, Nichelli PF, Grafman J. Apathy and disinhibition in frontotemporal dementia: Insights into their neural correlates. Neurology 2008;71:736-742.

42. Lyketsos CG, Lopez O, Jones B, Fitzpatrick AL, Breitner J, DeKosky S. Prevalence of neuropsychiatric symptoms in dementia and mild cognitive impairment: results from the cardiovascular health study. JAMA 2002; 288:1475-1483.

43. Kaufer DI, Cummings JL, Ketchel P, Smith V, MacMillan A, Shelley T, et al. Validation of the NPI-Q, a brief clinical form of the Neuropsychiatric Inventory. J Neuropsychiatry Clin Neurosci 2000;12:233-239. 